CrossMark

$\leftarrow$ click for updates

Cite this: Dalton Trans., 2014, 43, 15004

Received 18th April 2014,

Accepted 9th July 2014

DOI: $10.1039 / c 4 d t 01149 j$

www.rsc.org/dalton

\title{
Assembly, characterization, and electrochemical properties of immobilized metal bipyridyl complexes on silicon(111) surfaces $\uparrow$
}

\author{
Judith R. C. Lattimer, $\neq^{\mathrm{a}, \mathrm{b}}$ James D. Blakemore, $t^{\mathrm{a}, \mathrm{b}}$ Wesley Sattler, ${ }^{\mathrm{a}, \mathrm{b}}$ Sheraz Gul, ${ }^{\mathrm{c}}$ \\ Ruchira Chatterjee, ${ }^{c}$ Vittal K. Yachandra, ${ }^{c}$ Junko Yano, ${ }^{c}$ Bruce S. Brunschwig, ${ }^{{ }^{b}}$ \\ Nathan S. Lewis ${ }^{\star a, b, d}$ and Harry B. Gray*a,b
}

\begin{abstract}
Silicon(111) surfaces have been functionalized with mixed monolayers consisting of submonolayer coverages of immobilized 4-vinyl-2,2'-bipyridyl (1, vbpy) moieties, with the remaining atop sites of the silicon surface passivated by methyl groups. As the immobilized bipyridyl ligands bind transition metal ions, metal complexes can be assembled on the silicon surface. X-ray photoelectron spectroscopy (XPS) demonstrates that bipyridyl complexes of $\left[C p^{*} R h\right],\left[C p^{*} \mid r\right]$, and $\left[R u(a c a c)_{2}\right]$ were formed on the surface $\left(C p^{*}\right.$ is pentamethylcyclopentadienyl, acac is acetylacetonate). For the surface prepared with Ir, X-ray absorption spectroscopy at the Ir $L_{\text {III }}$ edge showed an edge energy as well as post-edge features that were essentially identical with those observed on a powder sample of [C $\left.p^{*} \mid \operatorname{rr}(\mathrm{bpy}) \mathrm{Cl}\right] \mathrm{Cl}$ (bpy is 2,2'-bipyridyl). Chargecarrier lifetime measurements confirmed that the silicon surfaces retain their highly favorable photoelectronic properties upon assembly of the metal complexes. Electrochemical data for surfaces prepared on highly doped, $\mathrm{n}$-type $\mathrm{Si}(111)$ electrodes showed that the assembled molecular complexes were redox active. However the stability of the molecular complexes on the surfaces was limited to several cycles of voltammetry.
\end{abstract}

\section{Introduction}

Many designs for photoelectrochemical fuel-generation devices rely upon one or more semiconductors to absorb and convert photon energy into separated charge carriers. The separated charge carriers are, in turn, coupled to surface-bound electrocatalysts that produce oxygen and fuels either from water or from water and $\mathrm{CO}_{2}$. Silicon is a well-understood and technologically important semiconductor that can efficiently absorb visible light, and is thus an attractive material for use in solar-fuels devices. ${ }^{1}$ However, silicon is a poor catalyst for fuel-forming reactions and is not stable under ambient con-

\footnotetext{
${ }^{a}$ Division of Chemistry and Chemical Engineering, California Institute of Technology, Pasadena, California 91125, USA.E-mail: bsb@caltech.edu,nslewis@caltech.edu, hbgray@caltech.edu

${ }^{b}$ Beckman Institute, California Institute of Technology, Pasadena, California 91125, USA

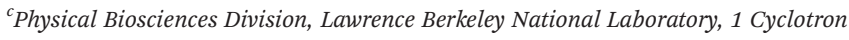
Road, Mail Stop 66R0200, Berkeley, California 94720, USA

${ }^{d}$ Kavli Nanoscience Institute, California Institute of Technology, Pasadena, California 91125, USA

$\dagger$ Electronic supplementary information (ESI) available: Detailed experimental information; additional XPS and electrochemistry data. See DOI: 10.1039/c4dt01149j

$\$$ These authors contributed equally.
}

ditions unless properly passivated. Facile routes to prepare catalyst-functionalized silicon surfaces that are free of both electronic defects and unwanted chemically reactive sites would therefore advance the development of solar-fuels devices. If inorganic or organometallic catalysts can be immobilized on electrode surfaces without loss of catalytic activity, assembled photocathodes could perform reductive, fuel-forming reactions such as the conversion of protons to dihydrogen, or the reduction of $\mathrm{CO}_{2}$ to liquid fuels. ${ }^{2}$

Retaining the activity of molecular catalysts after binding the species to a surface remains challenging, due to the limited compatibility of most such species with conditions that are suitable for covalently attaching ligands to silicon surfaces. ${ }^{3}$ Furthermore, the proper coordination environment around the metal center must be maintained during electrochemical cycling, to prevent ligand-exchange processes that may cause either the loss of catalyst molecules from the surface or the formation of secondary heterogeneous materials. ${ }^{4,5}$

A two-step halogenation/methylation procedure can be used to terminate essentially all of the atop sites on a $\operatorname{Si}(111)$ surface with methyl groups. ${ }^{6}$ The resulting methyl-terminated surfaces are protected against oxidation by air and resist oxidation during electrochemical and photoelectrochemical applications. ${ }^{7}$ Methyl groups are the only saturated alkyl units 

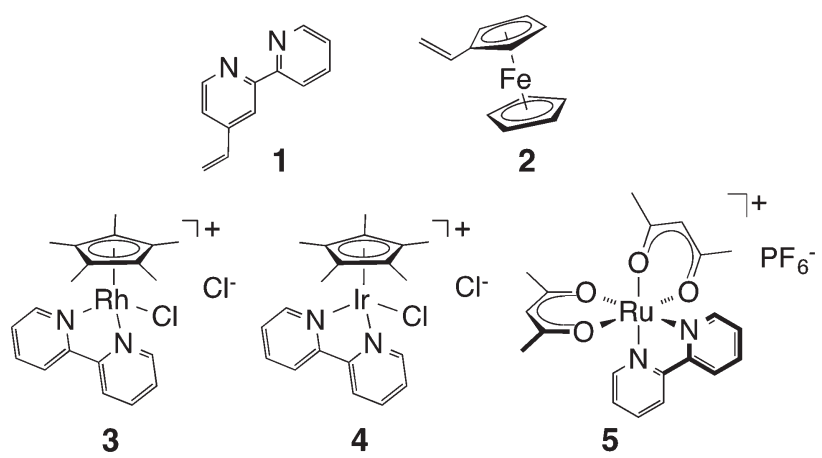

Fig. 1 Structures of 1-5

that sterically can terminate all of the $\mathrm{Si}(111)$ atop sites, so mixed monolayers that contain both protective methyl groups and reactive sites have been used as handles for secondary functionalization such as catalyst binding. ${ }^{8}$ This strategy imparts the $\mathrm{Si}(111)$ surface with the stability of full Si-C termination and the functionality of a molecular catalyst. For example, mixed methyl/thienyl monolayers can be subsequently functionalized with vinyl-tagged reagents, such as vinylferrocene, via bromination and subsequent Heck coupling (2, see Fig. 1). ${ }^{9}$ Similarly, mixed methyl/ferrocenyl monolayers prepared from chlorine-terminated silicon surfaces have ferrocenyl moieties on up to $30 \%$ of the $\mathrm{Si}(111)$ atop sites, with the remaining sites passivated by methyl groups. ${ }^{10}$

We report herein the preparation of mixed monolayers on $\mathrm{Si}(111)$ by combining the chlorine-termination procedure with the UV light-induced attachment of vinyl-tagged reagents. In this process, the chlorinated surface (i.e., all atop sites terminated as $\mathrm{Si}-\mathrm{Cl}$ ) is briefly exposed to $\mathrm{CH}_{3} \mathrm{MgCl}$ to yield a predominantly methyl-terminated surface with some remaining unreacted Si-Cl bonds. UV light-induced modification of this surface with vinylferrocene (2), in a hydrosilylation-like reaction, produces submonolayer coverages of attached ferrocenyl moieties, mixed with terminal methyl groups (see ESI†).

In this work, the method has been used to attach, 4-vinyl2,2'-bipyridyl (1) to $\mathrm{Si}(111)$ (Scheme 1). The resulting immobilized bipyridyl ligand can form complexes with metal reagents on the surface. Hence, immobilized analogues of pentamethylcyclopentadienyl rhodium (3) and iridium (4) complexes, as well as a ruthenium complex (5), can be assembled on the surface. The soluble rhodium complex has been shown by Grätzel, Kölle, and others to serve as a proton-reduction catalyst, ${ }^{11}$ and so the stability of the surface-bound $\left[\mathrm{Cp}^{*} \mathrm{Rh}\right]$ system was also investigated in the presence of $p$-toluenesulfonic acid.

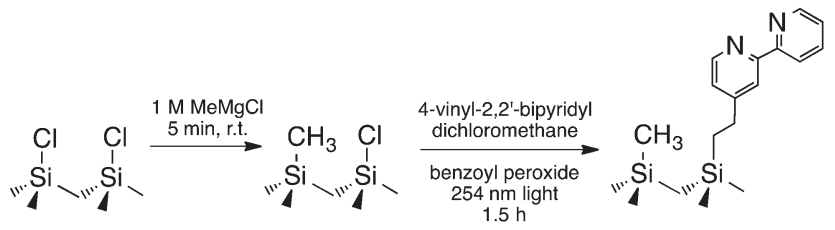

Scheme 1 Functionalization of silicon(111) with 4-vinyl-2,2'-bipyridyl.
Importantly, the silicon(111) retains its favorable photoelectronic properties upon assembly of the catalytically-relevant metal complexes on the surface. This new result builds on prior work that examined surface functionalization with alkyl groups and noncatalytic redox couples. ${ }^{6,9,10}$ Moreover, comparison of the immobilized metal complexes with their soluble analogues supports the molecular nature of the immobilized material, based on both X-ray spectroscopy and electrochemical data.

\section{Experimental}

Detailed descriptions of the reagents and instruments, as well as the techniques used to determine surface-recombination velocities and to perform electrochemical experiments, are provided in the ESI. $\dagger$ All of the functionalized Si(111) samples that were investigated by XPS were rinsed with trichloroethylene prior to characterization.

\section{Attachment of vinylferrocene and 4-vinyl-2,2'-bipyridyl to silicon(111)}

Mixed methyl/bipyridyl- and mixed methyl/ferrocenyl-functionalized $\mathrm{Si}(111)$ samples were prepared as described in the ESI. $\dagger$ Briefly, pieces of clean, H-terminated Si(111) were transferred to a $\mathrm{N}_{2}(\mathrm{~g})$-purged flush box and treated to yield Cl-terminated $\mathrm{Si}(111)$ surfaces. The $\mathrm{Cl}-\mathrm{Si}(111)$ surfaces were further treated to yield partially $\mathrm{CH}_{3}$-terminated $\mathrm{Si}(111)$ surfaces. The mixed $\mathrm{Cl} / \mathrm{CH}_{3}$-functionalized $\mathrm{Si}(111)$ surfaces were then exposed to UV light in the presence of either vinylferrocene (2) or 4-vinyl-2,2'-dipyridyl (1), to yield mixed methyl/ferrocenyland mixed methyl/bipyridyl-functionalized surfaces, respectively (Scheme 1). These functionalized Si samples were cleaned and removed from the flush box.

\section{Metallation of immobilized bipyridyl}

Prior to metallation, the mixed methyl/bipyridyl-functionalized $\mathrm{Si}(111)$ samples were removed from the $\mathrm{N}_{2}(\mathrm{~g})$-purged flush box and were cleaned by sonication for $10 \mathrm{~min}$ each in $\mathrm{CH}_{2} \mathrm{Cl}_{2}$, $\mathrm{CH}_{3} \mathrm{OH}$, and $\mathrm{H}_{2} \mathrm{O}$. The samples were immersed in a $10 \mathrm{mM}$ solution of either $\left[\mathrm{Cp}^{*} \mathrm{RhCl}_{2}\right]_{2}$ or $\left[\mathrm{Cp}^{*} \mathrm{IrCl}_{2}\right]_{2}$ (see ESI $\dagger$ ) in $\mathrm{CH}_{2} \mathrm{Cl}_{2}$ for $1 \mathrm{~h}$, and then sonicated for 10 min each in $\mathrm{CH}_{2} \mathrm{Cl}_{2}$, $\mathrm{CH}_{3} \mathrm{OH}$, and $\mathrm{H}_{2} \mathrm{O}$. Characterization by XPS was performed after removal of the functionalized $\mathrm{Si}(111)$ samples from the flush box and exposure to ambient conditions. [ $\mathrm{Ru}(\mathrm{acac})_{2^{-}}$ (bpy) $]^{+}$(acac is acetylacetonate) was assembled on the mixed surface via treatment with $\mathrm{Ru}(\mathrm{acac})_{2}(\mathrm{coe})_{2}$ (coe is cis-cyclooctene; see ESI $\dagger$ for details). ${ }^{12-14}$

\section{Results}

\section{$\mathrm{X}$-ray analyses of functionalized $\mathrm{Si}(111)$ surfaces}

Methyl- and mixed methyl/bipyridyl-functionalized surfaces. Fig. 2 shows the X-ray photoelectron (XP) spectra for methyl and mixed methyl/bipyridyl $\mathrm{Si}(111)$ surfaces, respectively. The 


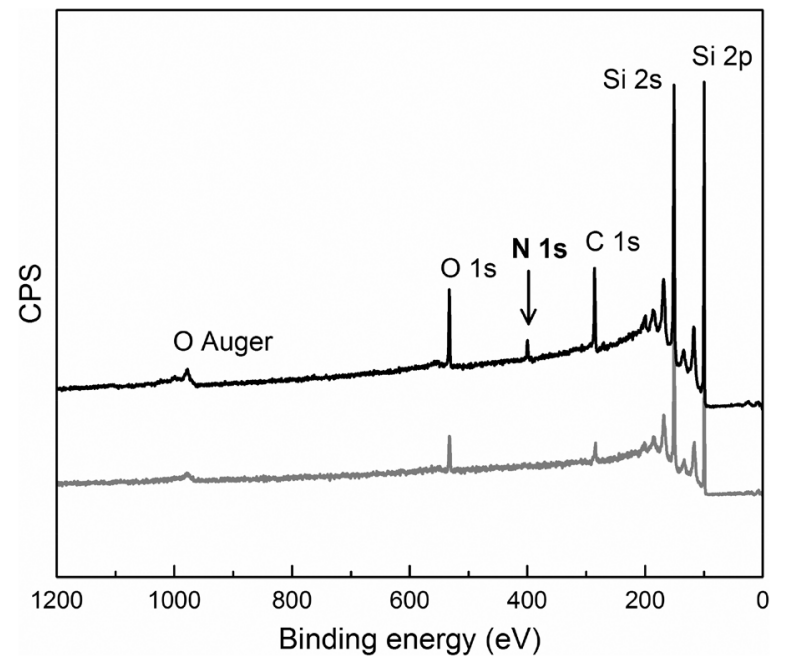

Fig. 2 X-ray photoelectron spectra of a mixed methyl/bipyridyl silicon(111) surface (upper black spectrum) and methyl-terminated silicon(111) surface (lower gray spectrum). No nitrogen was detected on the methylated surface.

survey spectra exhibited peaks corresponding to $\mathrm{Si}$ (2p, $100 \mathrm{eV}), \mathrm{C}(1 \mathrm{~s}, 285 \mathrm{eV})$, and $\mathrm{O}$ (1s, $532 \mathrm{eV})$. A smaller peak near $400 \mathrm{eV}$ was consistent with an N 1s assignment. High-resolution spectra resolved the $\mathrm{N}$ 1s region (see Fig. 5 top panel) with a major component at $399.8 \mathrm{eV}$, consistent with nitrogen of the free-base bipyridine, and a shoulder at $401 \mathrm{eV}$. Using methods described previously ${ }^{10}$ and detailed in the ESI, $\dagger$ typical surface coverages for the bipyridyl ligand (assuming two $\mathrm{N}$ atoms per bipyridine) were equivalent to $10-35 \%$ of a monolayer. ${ }^{15}$

A high-resolution scan of the $\mathrm{Si} 2 \mathrm{p}$ region revealed a very small feature at $102.9 \mathrm{eV}$, corresponding to $<1 \%$ of a monolayer of surface oxide. A high-resolution scan of the $\mathrm{Cl} 2 \mathrm{~s}$ region indicated a small amount (35\% of a monolayer) of $\mathrm{Cl}$ remaining on the surface $(\mathrm{Cl} 2 \mathrm{~s}, 271.1 \mathrm{eV})$, attributable to the presence of unreacted surface $\mathrm{Si}-\mathrm{Cl}$ sites, incorporation of chlorine into the organic surface components under the conditions of the radical reaction, or trace solvent contamination. Consistent with prior reports, ${ }^{6 a, c_{2} f}$ a fully methylated $\mathrm{Si}(111)$ surface showed only signals corresponding to $\mathrm{Si}, \mathrm{C}$, and $\mathrm{O}$.

Rhodium-modified mixed methyl/bipyridyl-functionalized surfaces. Fig. 3 shows typical XP survey spectra for Rh-modified $\mathrm{Si}(111)$ mixed monolayer surfaces. For comparison purposes, a methylated surface was also exposed to the Rh precursor because nonspecific binding or physisorption of $\left[\mathrm{Cp}{ }^{*} \mathrm{Rh}\right]$ species might also occur on the surface (Fig. 3, gray). The wafer was cleaned as in the case of the mixed monolayer surface.

The survey spectrum for the Rh-modified mixed monolayer Si(111) surface showed a feature centered near $312 \mathrm{eV}$, indicative of $\mathrm{Rh}$ present on the surface. $\mathrm{Cl} 2 \mathrm{~s}$ and $2 \mathrm{p}$ peaks were also present, consistent with the use of the chloride-containing $\left[\mathrm{Cp}^{*} \mathrm{RhCl}_{2}\right]_{2}$ reagent to give the chloride complex. The Rhtreated mixed monolayer surface exhibited an increase in the

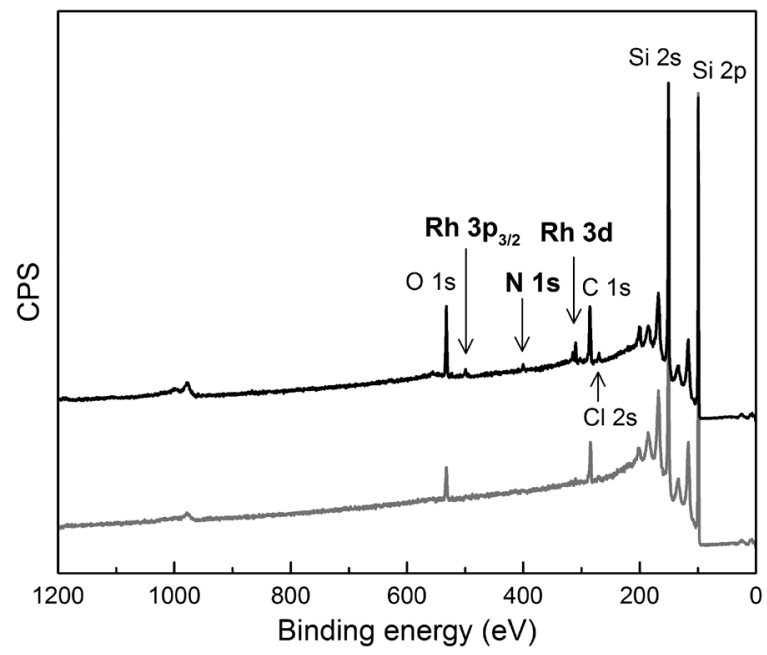

Fig. 3 X-ray photoelectron spectra of a methyl/bipyridyl silicon(111) surface (upper black line) and a methylated surface (lower gray line) exposed to a solution of $\left[\mathrm{Cp}^{*} \mathrm{RhCl}_{2}\right]_{2}$ for $1 \mathrm{~h}$. New peaks in the Rh $3 \mathrm{~d}$ region are clearly visible in the survey scan for the mixed surface only.

amount of surface oxide compared to the surface composition before treatment with $\left[\mathrm{Cp}^{*} \mathrm{RhCl}_{2}\right]_{2}$, with the Si oxide signal increasing from $\sim 1 \%$ to $14 \%$ of a monolayer. No $\mathrm{Rh}$ or $\mathrm{Cl}$ signals were detected in the XPS spectra (survey or high-resolution; see ESI $\dagger$ ) for the $\left[\mathrm{Cp}^{*} \mathrm{RhCl}_{2}\right]_{2}$-exposed $\mathrm{CH}_{3}-\mathrm{Si}(111)$ surface, suggesting that nonspecific binding did not play a major role in immobilization of $\left[\mathrm{Cp}^{*} \mathrm{Rh}\right]$ species in this system. Also in contrast to the mixed monolayer Si surface, no surface oxide was detected on the Rh-treated $\mathrm{CH}_{3}-\mathrm{Si}(111)$ surface.

In high-resolution XPS data, only one signal was visible in the $\mathrm{Rh}$ 3d region, with peaks centered at 310.1 and $314.8 \mathrm{eV}$ (Fig. 4, upper panel). The spin-orbit separation of $4.7 \mathrm{eV}$ was consistent with the behavior expected for Rh compounds, and the peak positions were consistent with $\mathrm{Rh}$ in the +3 oxidation state. Only a single contribution was observed for both the $3 \mathrm{~d}_{5 / 2}$ and $3 d_{3 / 2}$ peaks, suggesting only a single type of Rh species on the surface. A peak area ratio of $3: 2$ was typically found, as expected for $3 \mathrm{~d}$ peaks. The spectra for the Rh-modified mixed methyl/bipyridyl-functionalized $\mathrm{Si}(111)$ surface was also compared to that of a sample of $\left[\mathrm{Cp}^{*} \mathrm{Rh}(\mathrm{bpy}) \mathrm{Cl}\right] \mathrm{Cl}$ that had been drop-cast from a dilute solution onto a piece of clean copper foil. The $\mathrm{Rh} 3 \mathrm{~d}$ region for the $\left[\mathrm{Cp}^{*} \mathrm{Rh}(\mathrm{bpy}) \mathrm{Cl}\right] \mathrm{Cl}$ film was virtually identical to that observed for the functionalized $\mathrm{Si}(111)$ surface, with peaks at 310.1 and $314.8 \mathrm{eV}$ (Fig. 4, lower panel). As a control, XP spectra were also obtained for a drop-cast sample of $\left[\mathrm{Cp}^{*} \mathrm{RhCl}_{2}\right]_{2}$, but the Rh $3 \mathrm{~d}$ signals in XPS (see ESI $\dagger$ ) were broader than those for compound 3 and were not well described by a single-component fit.

The N 1s high-resolution XP spectra were also compared for the mixed methyl/bipyridyl surface before and after Rh modification. Before metallation, two contributions were observed in the $\mathrm{N} 1 \mathrm{~s}$ region, with a dominant contribution at $399.7 \mathrm{eV}$ and a smaller component at $400.7 \mathrm{eV}$ (Fig. 5, upper panel). The binding energy of the larger component was consistent with 


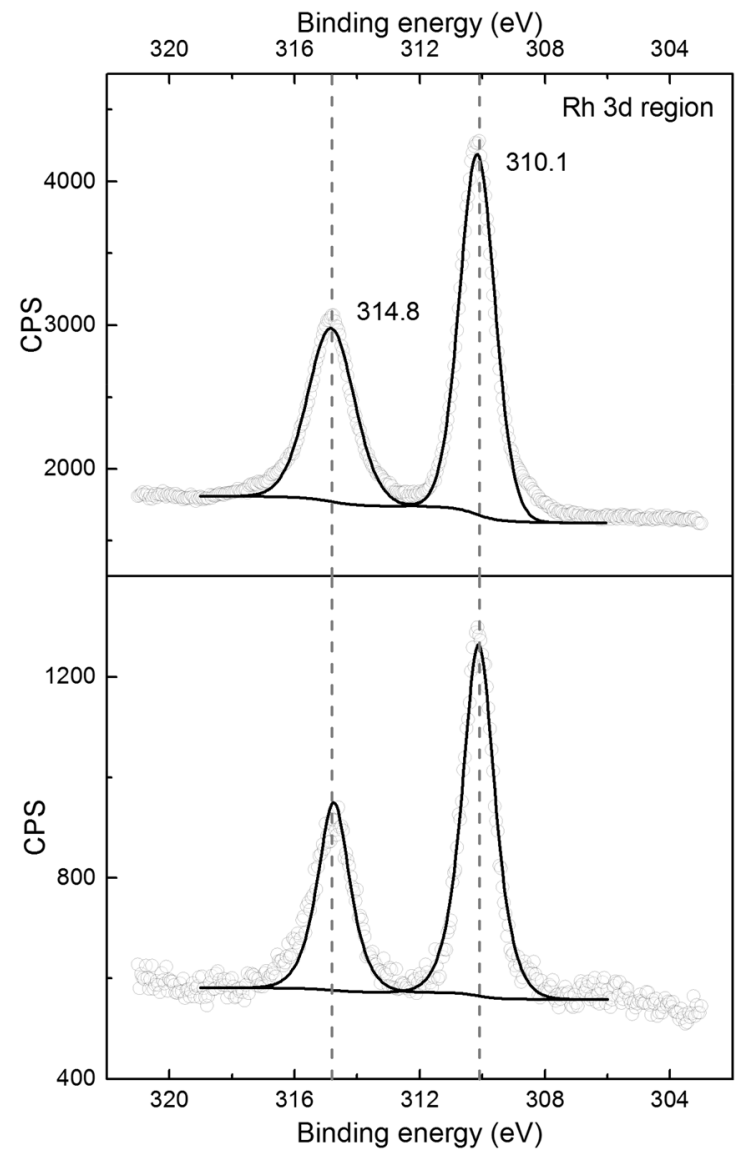

Fig. 4 Comparison of Rh $3 \mathrm{~d}$ XP spectra for a mixed methyl/bipyridyl surface after exposure to a solution containing $\left[\mathrm{Cp} * \mathrm{RhCl}_{2}\right]_{2}$ as described in the main text (upper panel) and $[\mathrm{Cp} * \mathrm{Rh}(\mathrm{bpy}) \mathrm{Cl}] \mathrm{Cl}$ drop-cast onto copper foil (lower panel).

free, unmetallated bipyridyl, by comparison with a value of $399.4 \mathrm{eV}$ observed previously for the free-base nitrogen of $2,2^{\prime}$ bipyridine. $^{16}$

Following exposure of the mixed methyl/bipyridyl surface to $\left[\mathrm{Cp}^{*} \mathrm{RhCl}_{2}\right]_{2}$, the dominant nitrogen signal shifted to a higher binding energy, $400.6 \mathrm{eV}$ (Fig. 5, middle panel), suggesting that most of the nitrogen on this surface was bound to Rh. A shoulder remained at the lower binding energy (fit to 399.4 $\mathrm{eV}$ ), corresponding to some free-base bipyridine remaining on the surface. For the model complex $\left[\mathrm{Cp}^{*} \mathrm{Rh}(\mathrm{bpy}) \mathrm{Cl}\right] \mathrm{Cl}$ dropcast onto copper foil, XPS analysis resulted in a single $\mathrm{N}$ signal at $400.4 \mathrm{eV}$ (Fig. 5, lower panel). Thus, the higher binding energy $\mathrm{N}$ 1s peak can be assigned to bipyridine bound to the $\mathrm{Rh}$ in the surface-immobilized bipyridyl moiety on the $\mathrm{Si}(111)$ mixed monolayer surface.

The surface coverages of $\mathrm{Rh}$ and of metal-bound nitrogen in bipyridyl were generally self-consistent. The surface coverage of rhodium was $32 \%$, while the bound bipyridine coverage was estimated at $38 \%$. In this calculation, all of the nitrogen signals were assumed to arise from bipyridyl (i.e., $2 \mathrm{~N}$ atoms per bipyridyl; with the total bound $\mathrm{N}$ signal at $400.6 \mathrm{eV}$ producing $76 \%$ of a monolayer). Conversely, only $16 \%$ of a monolayer of free bipyridyl was observed. Notably, $\sim 1$ monolayer of

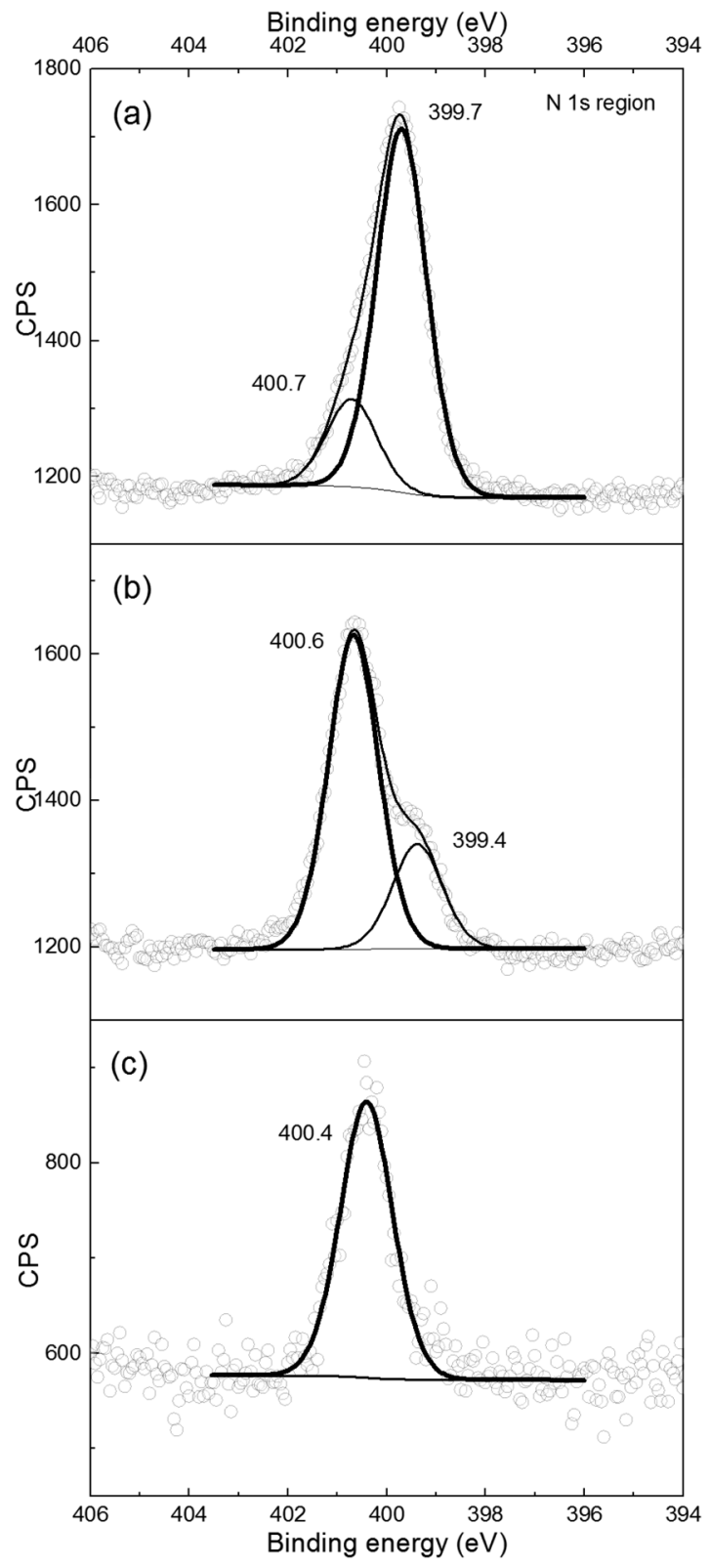

Fig. 5 Comparison of $\mathrm{N}$ 1s XP spectra for a mixed methyl/bipyridyl surface before (upper panel, a) and after (middle panel, b) exposure to a solution containing $\left[\mathrm{Cp} * \mathrm{RhCl}_{2}\right]_{2}$ as described in the main text. Lower panel, c: N 1s XP spectrum for [Cp*Rh(bpy)Cl]Cl drop-cast onto copper foil.

$\mathrm{Cl}$ was detected in the $\mathrm{Cl} 2 \mathrm{~s}$ region, in accord with expectations that each $\left[\mathrm{Cp}^{*} \mathrm{Rh}\right]$ complex should have two chlorides for charge balance.

Soaking the mixed methyl/bipyridyl surface in a $20 \mathrm{mM}$ solution of $\left[\mathrm{Cp}^{*} \mathrm{Rh}(\mathrm{bpy}) \mathrm{Cl}\right] \mathrm{Cl}$ (instead of $\left[\mathrm{Cp}^{*} \mathrm{RhCl}_{2}\right]_{2}$; see ESI $\dagger$ ) resulted in only $\sim 2 \%$ of a monolayer coverage of $\mathrm{Rh}$, suggesting that ligand exchange with the bipyridine compounds was relatively slow.

Iridium-modified mixed methyl/bipyridyl-functionalized surfaces. Methyl/bipyridyl surfaces were interrogated by XPS after exposure to $\left[\mathrm{Cp}^{*} \mathrm{IrCl}_{2}\right]_{2}$. Peaks corresponding to surface- 
bound Ir were observed in the Ir $4 \mathrm{f}(64 \mathrm{eV})$, Ir $4 \mathrm{~d}(307 \mathrm{eV})$, and Ir $4 \mathrm{p}(498 \mathrm{eV})$ regions (see $\mathrm{ESI} \dagger$ for all spectra). Strong signals were also observed for $\mathrm{Cl}$ (2s and $2 \mathrm{p}$ ), in addition to the $\mathrm{Si}, \mathrm{O}$, $\mathrm{C}$, and $\mathrm{N}$ signals observed on the surface prior to metallation. High-resolution XP spectra of the Ir $4 \mathrm{f}$ region showed single signals at 62.8 and $65.9 \mathrm{eV}$. These peaks matched well with the Ir $4 \mathrm{f}$ XP spectra obtained for the model compound [Cp* $\operatorname{Ir}(\mathrm{bpy})$ $\mathrm{Cl}$ Cl drop-cast onto high-purity $\mathrm{Cu}$ foil (peaks at 62.9 and $65.9 \mathrm{eV}$ ). High-resolution scans of the $\mathrm{N} 1 \mathrm{~s}$ region showed three contributions: a large feature at $400.8 \mathrm{eV}$, a smaller one at $399.6 \mathrm{eV}$, and a minor shoulder at $402.2 \mathrm{eV}$. The model compound $\left[\mathrm{Cp}^{*} \operatorname{Ir}(\mathrm{bpy}) \mathrm{Cl}\right] \mathrm{Cl}$ showed a single peak at $400.7 \mathrm{eV}$. Thus, as in the case of Rh, the dominant peak at $400.8 \mathrm{eV}$ for the metallated surface corresponded to iridium-bound bipyridyl on the surface, while the signal at $399.6 \mathrm{eV}$ matched well with that for metal-free immobilized bipyridyl. An XP spectrum of a film of 2,2'-bipyridyl- $N$-oxide (drop-cast on copper foil; see $\mathrm{ESI}_{\dagger} \dagger$ ) yielded two N 1s signals, one at $400.4 \mathrm{eV}$, corresponding to the free-base nitrogen, as well as a peak at $403.6 \mathrm{eV}$ for the $N$-oxide. The surface peak at $402.2 \mathrm{eV}$ was thus not located at sufficiently high binding energy to be assigned to an immobilized $N$-oxide of bipyridyl.

Quantitative analysis of the surface coverage based on the Ir signal yielded an estimate of $34 \%$ of a monolayer of iridium(III), while an analysis based on the $\mathrm{N}$ signal yielded an estimated total $\mathrm{N}$ coverage of $62 \%$ of a monolayer. $17 \%$ of a monolayer of Ir-bound bipyridyl was calculated based on the peak at $400.8 \mathrm{eV}, 7 \%$ of a monolayer of free-base bipyridyl was estimated based on the peak at $399.6 \mathrm{eV}$, with roughly $7 \%$ of a monolayer for the unassigned and poorly resolved shoulder at $402.2 \mathrm{eV}$. As in the case of the Rh-modified surface, an increase in the Si oxide signal from $\sim 13$ to $\sim 21 \%$ was observed upon metallation.

Ir $\mathrm{L}_{\mathrm{III}}$-edge X-ray absorption spectroscopy (XAS) provided further evidence for assembly of the desired complex on the surface. Fig. 6 shows the edge and post-edge data for a powder of isolated $\left[\mathrm{Cp}^{*} \operatorname{Ir}(\mathrm{bpy}) \mathrm{Cl}\right] \mathrm{Cl}$ (4, black line), while data for the analogous $\left[\mathrm{Cp}^{*} \mathrm{Ir}\right]$-modified mixed methyl/bipyridyl surface are shown in blue points. In both cases, iridium was characterized by a peak energy of $11215 \mathrm{eV}$, values consistent with iridium in the +3 oxidation state. ${ }^{17}$ In addition, the post-edge features were similar for $\mathbf{4}$ and the silicon-immobilized analogue, suggesting a similar environment in the first coordination shell of iridium in both cases.

Ruthenium-modified mixed methyl/bipyridyl-functionalized surfaces. As for the $\left[\mathrm{Cp}^{*} \mathrm{Rh}\right]$ - and $\left[\mathrm{Cp}^{*} \mathrm{Ir}\right]$-modified surfaces, XP spectra were collected for the Ru-modified mixed methyl/ bipyridyl-functionalized $\mathrm{Si}(111)$ surface. $\mathrm{Ru} 3 \mathrm{p}$ peaks at 463.2 and $485.4 \mathrm{eV}$ appeared following metallation (spectra in ESI $\dagger$ ), consistent with $\mathrm{Ru}$ in the +3 oxidation state. Comparison spectra for the model compound $\mathbf{5}$ showed similar $\mathrm{Ru} 3 \mathrm{p}$ peaks at 463.3 and $485.6 \mathrm{eV}$. The surface $\mathrm{N}$ 1s region exhibited a dominant signal at $400.5 \mathrm{eV}$, corresponding to the nitrogen of metallated bipyridyl, and a smaller contribution at $399.6 \mathrm{eV}$, attributable to free-base bipyridyl. The 2,2'-bipyridyl $\mathrm{N} 1 \mathrm{~s}$ signal for the model compound 5 was observed at $400.5 \mathrm{eV}$.

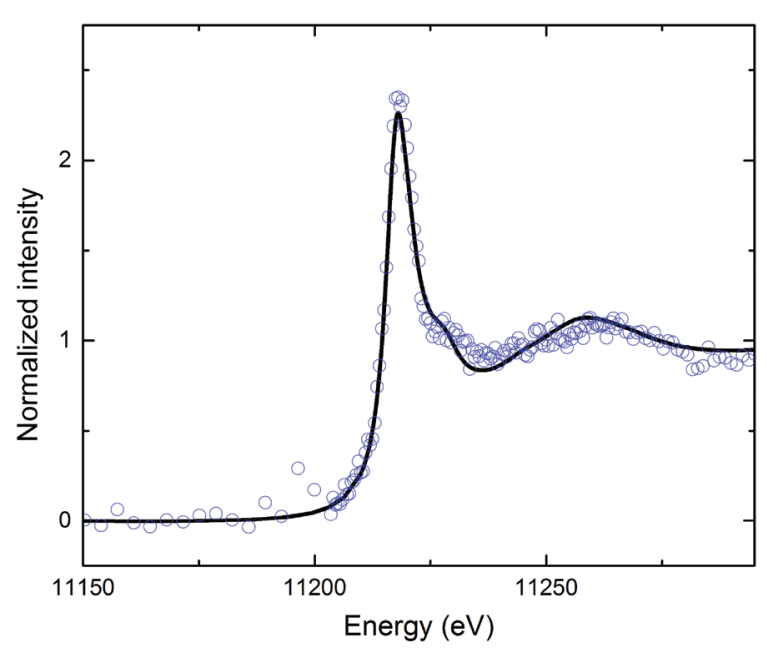

Fig. 6 Comparison of $\mathrm{Ir} \mathrm{L}_{111}$-edge XAS results for the mixed methyl/ bipyridyl surface exposed to $\left[\mathrm{Cp}^{*} \mid \mathrm{ICl}_{2}\right]_{2}$ (blue points) and the $[\mathrm{Cp} * \mathrm{I}(\mathrm{bpy})-$ $\mathrm{Cl} \mathrm{Cl}$ model complex 4 (black line).

Quantitative analysis of the surface coverage based on the $\mathrm{Ru}$ signals yielded an estimate that $21 \%$ of a monolayer of $\mathrm{Ru}(\mathrm{III})$ was present on the metallated surface, while an analysis based on the $\mathrm{N}$ signal yielded an estimated total $\mathrm{N}$ coverage of $71 \%$ of a monolayer. $26 \%$ of a monolayer of Ru-bound immobilized bipyridyl was calculated based on the dominant peak at $400.5 \mathrm{eV}, 6 \%$ of a monolayer of free-base bipyridyl was estimated based on the peak at $399.6 \mathrm{eV}$, with $4 \%$ of a monolayer for the shoulder at $402.1 \mathrm{eV}$ (see $\mathrm{ESI}^{\dagger}$ for $\mathrm{N}$ 1s XP spectrum).

Metallation of the surface with $\left[\mathrm{Ru}(\mathrm{acac})_{2}\left(\mathrm{CH}_{3} \mathrm{CN}\right)_{2}\right] \mathrm{OTf}$, which has been found to react in solution with 2,2'-bipyridyl at elevated temperature to produce soluble model $5,{ }^{18}$ was also attempted. However, no $\mathrm{Ru}$ was found on the mixed surface even after heating for many hours. This observation suggested that only reactions with bipyridine that are facile in solution can occur with the bipyridyl ligand immobilized using this process on mixed monolayer $\mathrm{Si}(111)$ surfaces.

\section{Stability of immobilized Rh compounds}

Table 1 summarizes the stability data obtained by XPS analysis of surfaces that were soaked in $0.1 \mathrm{M}(n-\mathrm{Bu})_{4} \mathrm{NPF}_{6}$ and $0.1 \mathrm{M}$ $(n \text {-Bu })_{4} \mathrm{NPF}_{6} / 3 \mathrm{mM}$-toluenesulfonic acid solutions. The Rh

Table 1 Summary of surface coverage data before and after the Rhmodified mixed methyl/bipyridyl surface was exposed to electrolyte or electrolyte plus acid. Error in the coverage data was estimated to be \pm 0.05 , except for Si oxide data, estimated at \pm 0.10

\begin{tabular}{llll}
\hline Feature & $\begin{array}{l}\text { As } \\
\text { prepared }\end{array}$ & $\begin{array}{l}\text { After soak in } \\
0.1 \mathrm{M} \mathrm{Bu}_{4} \mathrm{NPF}_{6}\end{array}$ & $\begin{array}{l}\text { After soak in } 0.1 \mathrm{M} \\
\mathrm{Bu}_{4} \mathrm{NPF}_{6}+3 \mathrm{mM} \\
\text { tosic acid }\end{array}$ \\
\hline Si oxide & 0.15 & 0.29 & 0.34 \\
Rh (Rh 3d) & 0.11 & 0.12 & 0.04 \\
Rh-bound bipy & 0.13 & 0.17 & 0.08 \\
Free bipy & 0.03 & 0.04 & 0.03 \\
Other N & 0 & 0.06 & 0
\end{tabular}


Table 2 Surface coverage and surface recombination velocity (S) data for surface preparations discussed in the main text

\begin{tabular}{llllc}
\hline Surface & $\begin{array}{l}\text { Surface } \\
\text { coverage of } \\
\text { bipyridyl }\end{array}$ & $\begin{array}{l}\text { Surface } \\
\text { coverage of } \\
\text { Rh or Fe }\end{array}$ & $\begin{array}{l}\text { Carrier } \\
\text { lifetime } \\
(\mathrm{ms})\end{array}$ & $\begin{array}{l}S \\
\left(\mathrm{~cm} \mathrm{~s}^{-1}\right)\end{array}$ \\
\hline Methyl & - & - & 0.771 & 23 \\
Methyl/bipyridyl & $0.12 \pm 0.05$ & - & 0.383 & 46 \\
$\begin{array}{l}\text { Methyl/bipyridyl + } \\
{[\text { Cp*Rh] }}\end{array}$ & $0.15 \pm 0.05$ & $0.1 \pm 0.05$ & 0.430 & 41 \\
$\begin{array}{l}\text { Methyl/ferrocenyl } \\
\text { Native oxide }\end{array}$ & - & $0.3 \pm 0.05$ & 0.294 & 60 \\
& - & - & 0.007 & 2600
\end{tabular}

assembled onto the surface was stable in $0.1 \mathrm{M}(n-\mathrm{Bu})_{4} \mathrm{NPF}_{6}$ and no major changes in surface coverage were observed compared to a fresh sample, except for an apparent increase in surface oxide, consistent with manipulation and cleaning in ambient air during the experiment. Exposure to $p$-toluenesulfonic acid for $1 \mathrm{~h}$, however, resulted in an apparent loss of about half of the initial amount of immobilized bipyridine, as well as some loss of surface-bound Rh.

\section{Charge-carrier lifetimes on surface-modified $\mathrm{Si}(111)$}

Table 2 presents the charge-carrier lifetimes and surfacerecombination velocities $(S)$ that were determined for the functionalized Si(111) surfaces (see the ESI $\dagger$ ). Surface states facilitate charge-carrier recombination, leading to short lifetimes, high $S$ values, and poor surface electronic properties. Thus, low $S$ values are characteristic of well-passivated, stable surfaces with few surface recombination sites.

On $\mathrm{CH}_{3}-\mathrm{Si}(111)$, for which essentially every atop $\mathrm{Si}$ site is terminated by a methyl group, the charge-carrier lifetimes were long $(\sim 0.7 \mathrm{~ms})$ and the $S$ values $\left(\sim 25 \mathrm{~cm} \mathrm{~s}^{-1}\right)$ were low, indicating a low electrically active surface-state density. ${ }^{7 b}$ In comparison, Si surfaces coated with a native silicon oxide exhibited short carrier lifetimes $(\sim 5 \mu \mathrm{s})$ and $S$ values approximately 100 times $\left(\sim 2500 \mathrm{~cm} \mathrm{~s}^{-1}\right)$ greater than exhibited by the $\mathrm{CH}_{3}-\mathrm{Si}(111)$ surface. The mixed methyl/bipyridyl-functionalized $\mathrm{Si}(111)$ surfaces had an $S$ value only twice as high as that of methyl-terminated silicon, suggesting high-quality, wellpassivated surfaces. The $S$ values for the mixed methyl/bipyridyl surfaces before metallation were virtually unchanged following reaction with $\left[\mathrm{Cp}^{*} \mathrm{RhCl}_{2}\right]_{2}: 46$ and $41 \mathrm{~cm} \mathrm{~s}^{-1}$, respectively. For comparison, a mixed methyl/ferrocenyl surface had a chargecarrier lifetime of $0.29 \mathrm{~ms}$ and an $S$ of $60 \mathrm{~cm} \mathrm{~s}^{-1}$. Overall, these low $S$ values indicated the successful assembly of a mixed methyl monolayer that protected the silicon against oxidation and, consequently, against the formation of surface states. The successful assembly should allow for facile electron transfer from the silicon to the attached redox couples.

\section{Electrochemistry of the immobilized complexes}

Mixed methyl/ferrocenyl-functionalized surfaces. A cyclic voltammogram for the mixed methyl/vinylferrocenyl-functionalized surface showed a reversible redox couple at $0.0 \mathrm{~V} v s$. $\mathrm{Fc}^{+/ 0}$ (see $\mathrm{ESI}^{\dagger}$ for data; $\mathrm{Fc}^{+/ 0}$ is ferrocenium/ferrocene). Scanning cathodically as far as $-2.0 \mathrm{~V} v s$. $\mathrm{Fc}^{+/ 0}$ did not result in any significant changes to the electrochemical response of the surface; thus the surface preparation was stable to the negative potentials that are suitable for reductive fuel-forming reactions. The peak current density varied linearly with the scan rate, as expected for a surface-attached redox couple, and in agreement with prior work on related mixed methyl/ferrocenyl systems. ${ }^{10}$ The anodic and cathodic current versus time scans were integrated independently to determine the total charge transferred to the surface-attached ferrocenyl groups, and that value was used to estimate the surface coverage of ferrocenyl groups as $75 \pm 5 \%$ of a monolayer. Cycling this surface 30 times to $-2.0 \mathrm{~V} v s$. $\mathrm{Fc}^{+/ 0}$ resulted in a slight decrease in the number of ferrocenyl groups attached to the surface, from $75 \pm 5$ to $70 \pm 5 \%$ of a monolayer in coverage.

Rhodium-modified mixed methyl/bipyridyl-functionalized surfaces. In $\mathrm{CH}_{3} \mathrm{CN}, 3$ undergoes a chemically reversible net two-electron reduction near $-1.2 \mathrm{~V} v s$. $\mathrm{Fc}^{+/ 0}$ from the starting rhodium(III) state to form a rhodium(I) complex, with concomitant loss of coordinated chloride or solvent. ${ }^{4,11,19}$ The redox couple also exhibited the expected square-root dependence on scan rate, indicating a diffusional process free of surface adsorption effects (see ESI $\dagger$ ). ${ }^{20}$ Similar data were obtained when methyl-terminated $\mathrm{p}^{+}$-type silicon(111) was used as the working electrode. In the presence of acid and reducing agent, 3 serves as a proton-reduction catalyst. ${ }^{11}$ As expected, the addition of acid to the solution resulted in loss of electrochemical reversibility, and an increase in current corresponding to catalysis (see ESI†).

This same redox process was apparent on the surface of silicon(111) as a redox couple centered at $-1.1 \mathrm{~V}$ vs. $\mathrm{Fc}^{+/ 0}$ (Fig. 7). On the first voltammetric scan from $-0.4 \mathrm{~V}$ to $-1.5 \mathrm{~V}$, background current flow in a second redox process was observed at $\sim-1.3 \mathrm{~V} v s$. $\mathrm{Fc}^{+/ 0}$ (possibly owing to reduction of free bipyridine). ${ }^{21}$ On the return anodic scan, a non-diffusional wave was observed near $-1 \mathrm{~V} v s$. $\mathrm{Fc}^{+/ 0}$. On subsequent cycles, the peak separation $\left(\Delta E_{\mathrm{p}}\right)$ for the redox process was $\sim 10 \mathrm{mV}$,

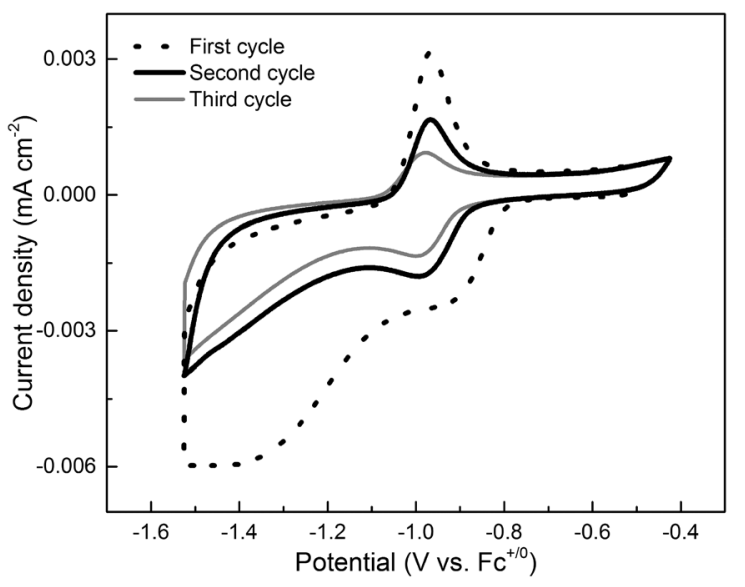

Fig. 7 Electrochemical response of a methyl/bipyridyl surface modified with $\left[\mathrm{Cp}^{\star} \mathrm{RhCl}_{2}\right]_{2}$. Black dotted line: first cycle; black solid line: second cycle; gray solid line: third cycle. See ESI $\dagger$ for details of the experimental conditions. 
consistent with a redox event arising from a non-diffusional species. However, upon continued cycling, the current flow in the key redox process decreased precipitously, suggesting that the redox-active species had been lost from the electrode surface during cycling. On the fourth and subsequent cycles, very little current above background levels was observed. If the scan limits were changed such that the potential was scanned from -0.2 to only $-1.3 \mathrm{~V} v s . \mathrm{Fc}^{+/ 0}$, the observed redox process was more stable and the redox couple was detectable for up to six complete cycles of voltammetry (see ESI $\dagger$ ).

The surface coverage of electroactive Rh was estimated to be $0.2 \%$ of a monolayer, using integrated current-time data from cyclic voltammetry (averaging both the anodic and cathodic currents over three complete cycles). This signal corresponded to only $\sim 1 \%$ of the coverage estimated from XPS $(0.21$ monolayers), indicating that not all of the metal present on the surface was electroactive.

The XP spectra collected after cyclic voltammetry for the $\left[\mathrm{Cp}^{*} \mathrm{Rh}\right]$-modified mixed surface showed no signal for $\mathrm{Rh}(\mathrm{Rh}$ 3d) and a trace signal for $\mathrm{N}$ ( $\mathrm{N}$ 1s) (see ESI $\dagger$ ). Thus both Rh and immobilized bipyridyl were lost from the surface upon redox cycling. Notably, the immobilized bipyridyl was also lost when the mixed surface was scanned reductively without metallation.

Iridium-modified mixed methyl/bipyridyl-functionalized surfaces. No electrochemical signals were observed when the Ir compounds were assembled on the surface. However, the reduction potential of the $\left[\mathrm{Cp}^{*} \mathrm{Ir}\right]$ complex has been found to be more negative than that of the $\left[\mathrm{Cp}^{*} \mathrm{Rh}\right]$ complex of $2,2^{\prime}$ bipyridyl. ${ }^{19,22}$ Reduction of unmetallated bipyridyl on the surface resulted in loss of material; hence, the lack of redox chemistry for the $\mathrm{Cp}^{*} \mathrm{Ir}$ complex is in accord with a reductively induced decomposition pathway. XP spectra showed no nitrogen or iridium on the surface following workup, further supporting this hypothesis.

Ruthenium-modified mixed methyl/bipyridyl-functionalized surfaces. The soluble $\mathrm{Ru}$ complex $\left[\mathrm{Ru}(\mathrm{acac})_{2}(\mathrm{bpy})\right] \mathrm{PF}_{6}(\mathbf{5})$ is more easily reduced than $\mathbf{3}$, and undergoes a redox process, cycling between $\mathrm{Ru}(\mathrm{III})$ and $\mathrm{Ru}(\mathrm{II})$ oxidation states, at around $-0.48 \mathrm{~V} v s$. $\mathrm{Fc}^{+/ 0}$ (Fig. 8, upper panel). As expected, this redox process for soluble $\mathbf{5}$ showed a squareroot dependence of peak current on scan rate (see ESI $\dagger$ ).

Redox cycling of the compound was observed during cyclic voltammetry performed using electrodes that were assembled with the $\mathrm{Ru}$ compound attached via immobilized bipyridyl ligands (Fig. 8, lower panel), with the half-wave potential centered at $-0.49 \mathrm{~V} v s . \mathrm{Fc}^{+/ 0}\left(\Delta E_{\mathrm{p}}=171 \mathrm{mV}\right)$. The peak separation of model compound 5 in solution was $71 \mathrm{mV}$ (Fig. 8, upper panel), suggesting slower electron transfer to the immobilized complex. While this redox couple persisted beyond ten complete cycles of voltammetry from -0.2 to $-0.9 \mathrm{~V}$ vs. $\mathrm{Fc}^{+/ 0}$, the signal was not sufficiently long-lived to allow more extensive characterization. Integration of the current-time data gave $0.2 \%$ of a monolayer of electroactive $\mathrm{Ru}$ on the surface, similar to the case of the Rh complex discussed above.

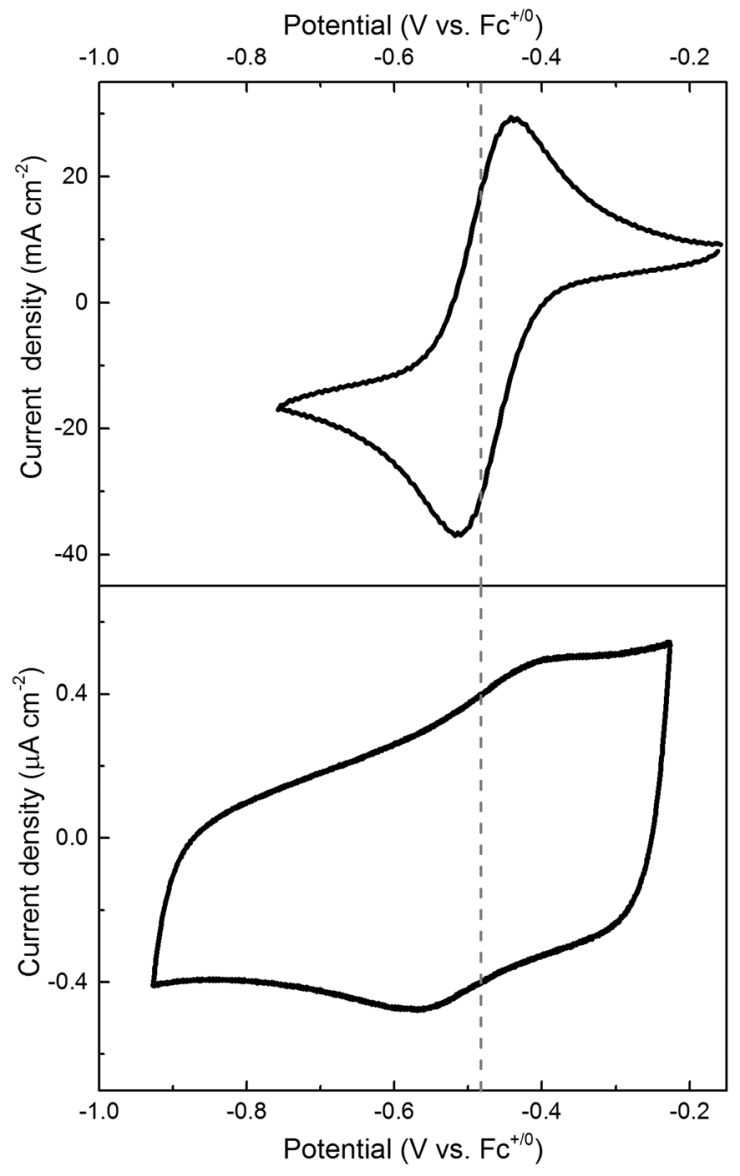

Fig. 8 Comparison of cyclic voltammetry of soluble model compound 5 (upper panel) and the mixed methyl/bipyridyl surface modified with $\mathrm{Ru}$ by treatment with $\mathrm{Ru}(\mathrm{acac})_{2}(\mathrm{coe})_{2}$ (lower panel). The scan rate in both cases was $100 \mathrm{mV} \mathrm{s}^{-1}$.

After the electrochemical study, XP spectra of the $\mathrm{Ru}$ treated electrode indicated that some of the attached complex remained on the surface. Before electrochemical cycling, the surface coverage of $\mathrm{Ru}$ was $21 \%$, in good agreement with the estimated $26 \%$ coverage of metal-bound bipyridine based on the $\mathrm{N} 1 \mathrm{~s}$ signal; the coverage of silicon oxide was $60 \%$, and the coverage by free-base bipyridine was estimated as $6 \%$. Following electrochemistry, the apparent coverage of silicon oxide increased slightly to $75 \%$, while the free-base bipyridine coverage was essentially invariant at $5 \%$. The metal-bound bipyridine coverage dropped slightly to $22 \%$, and the Ru coverage dropped to $11 \%$. The decreases in metal-bound $\mathrm{N}$ and $\mathrm{Ru}$ coverages were thus consistent with the eventual loss of the electrochemical signal. However, the lack of electroactivity of the remaining material suggested nonideal interfacial electron transfer.

\section{Discussion}

The development of methods for the robust attachment of molecular catalysts to (photo)electrode surfaces is an impor- 
tant challenge in solar-fuels research. The ability to attach catalysts to electrodes is anticipated to be a critical prerequisite for selective reduction of carbon dioxide, since few such heterogeneous catalysts have been reported. However, robust catalyst-immobilization procedures will be needed to provide stability under the extreme potentials and harsh conditions required for catalysis.

In this work, bipyridyl was first attached to the surface, and the desired metal complexes were subsequently assembled onto the mixed methyl/bipyridyl surface. The ligand was metallated readily via routes analogous to known solution chemistry. Only reactions that take place readily in solution can be expected to occur on the surface of an electrode with an immobilized ligand. Furthermore, steric restrictions not present in solution can be present on the surface, for example if multiple bipyridyl ligands are closely spaced, incomplete metallation could result.

The challenge illustrated by this work is that the assembled metal complexes were unstable under electrochemical cycling conditions. Since the immobilized metal complexes were rapidly lost from the surface upon electrochemical reduction, no further studies of their catalytic activities were possible. However, the stability improved when redox cycling could be performed at more positive potentials. This finding accords with the stability of mixed methyl/ferrocenyl surfaces, which have no internal redox events below the Fe(III/II) couple and are stable even to $-2 \mathrm{~V} v s$. $\mathrm{Fc}^{+/ 0}$.

A plausible mechanism for the loss of the assembled bipyridyl-metal complexes from the surface involves ligand-centered reduction of bipyridyl. In the electropolymerization of vinyl bipyridine reagents, reduction of the bipyridyl moiety results in increased reactivity of the appended vinyl group, a phenomenon exploited to drive the polymerization. ${ }^{23}$ Here, our surface-immobilized bipyridyl ligand presumably has a close connection with the silicon surface. Thus, bipyridyl-centered reduction may weaken the bonding with the $\mathrm{Si}(111)$ surface, and result in the observed surface instability. The Rh(I) form of model complex 3 is known to have bipyridine anion character, ${ }^{19}$ which would promote similar reactivity at the bipyridyl 4-position. Consistent with this proposal, greater stability was observed for the purely metal-centered $\mathrm{Ru}(\mathrm{III} / \mathrm{II})$ couple in model compound 5, since little bipyridyl-centred reduction is involved with this process. Reductive cycling of ferrocenylmodified electrodes over the same potentials did not result in loss of the redox couple from the surface, likely because the $\mathrm{Cp}$ ligand was not involved in any reduction events at reductive potentials. This observation highlights the opportunity to study redox processes under aqueous conditions with immobilized complexes that would ordinarily not be soluble/stable in aqueous conditions. If the surface can be stabilized against aqueous corrosion, new molecular electrochemical studies can be performed.

Future studies on surface immobilization could benefit by selection of partially insulating linkers between the immobilized ligand and the surface itself. Balancing the linker length and electron-transfer rate, though, may prove challenging.
Solution studies carried out on the metal complexes prior to immobilization will continue to be useful in this regard, since probing the electrochemical properties of the isolated catalyst will inform development of the surface chemistry.

\section{Conclusions}

Mixed methyl/bipyridyl monolayers capable of binding metal ions via chelation of surface-immobilized bipyridine to metal centers have been formed on $\mathrm{Si}(111)$ surfaces. Immobilized analogues of $\left[\mathrm{Cp}^{*} \mathrm{Rh}(\mathrm{bpy}) \mathrm{Cl}\right] \mathrm{Cl},\left[\mathrm{Cp}^{*} \operatorname{Ir}(\mathrm{bpy}) \mathrm{Cl}\right] \mathrm{Cl}$, and $\mathrm{Ru}-$ (acac) ${ }_{2}$ (bpy) have been assembled on $\mathrm{Si}(111)$ surfaces, as evidenced by XPS and XAS studies. Assembly of the metal complexes on the surface does not result in loss of the favorable photoelectronic properties of the silicon semiconductor, establishing their potential for use in photoelectrocatalytic devices. Electrochemical methods confirmed the assembly of the molecular $\left[\mathrm{Cp}^{*} \mathrm{Rh}\right]$ and $\left[\mathrm{Ru}(\mathrm{acac})_{2}\right]$ complexes, but their stability was limited. Thus, catalytically-relevant redox-active compounds can be assembled on silicon surfaces by attachment of the desired ligands followed by metallation. However, this approach requires development of stable ligand architectures that will be suitable for use in photoelectrocatalytic devices.

\section{Acknowledgements}

The authors thank Aaron Sattler for helpful discussions. Research was carried out in part at the Molecular Materials Research Center of the Beckman Institute at the California Institute of Technology. This work was supported by the NSF CCI Solar Fuels Program (CHE-1305124) and CCI Postdoctoral Fellowships to JDB and WS. The synchrotron facility was provided by the Stanford Synchrotron Radiation Laboratory (SSRL) at beam line 7-3. The SSRL Biomedical Technology program is supported by the National Institute of Health $(\mathrm{NIH})$, the National Center for Research Resources, and the DOE Office of Biological and Environmental Research. XAS work was funded by the Director, Office of Science, Office of Basic Energy Sciences (OBES), Division of Chemical Sciences, Geosciences, and Biosciences of the Department of Energy (DOE) under Contract DE-AC02-05CH11231.

\section{Notes and references}

1 (a) N. S. Lewis and D. G. Nocera, Proc. Natl. Acad. Sci. U. S. A., 2006, 103, 15729-15735; (b) H. B. Gray, Nat. Chem., 2009, 1, 7.

2 (a) M. G. Walter, E. L. Warren, J. R. McKone, S. W. Boettcher, Q. Mi, E. A. Santori and N. S. Lewis, Chem. Rev., 2010, 110, 6446-6473; (b) J. R. McKone, E. L. Warren, M. J. Bierman, S. W. Boettcher, B. S. Brunschwig, N. S. Lewis and H. B. Gray, Energy Environ. Sci., 2011, 4, 3573-3583; (c) W. Song, Z. Chen, M. K. Brennaman, 
J. J. Concepcion, A. O. T. Patrocinio, N. Y. M. Iha and T. J. Meyer, Pure Appl. Chem., 2011, 83, 749-768.

3 A. Krawicz, J. Yang, E. Anzenberg, J. Yano, I. D. Sharp and G. F. Moore, J. Am. Chem. Soc., 2013, 135, 11861-11868.

4 J. D. Blakemore, A. Gupta, J. J. Warren, B. S. Brunschwig and H. B. Gray, J. Am. Chem. Soc., 2013, 135, 1828818291.

5 N. D. Schley, J. D. Blakemore, N. K. Subbaiyan, C. D. Incarvito, F. D'Souza, R. H. Crabtree and G. W. Brudvig, J. Am. Chem. Soc., 2011, 133, 10473-10481.

6 (a) A. Bansal, X. Li, I. Lauermann, N. S. Lewis, S. I. Yi and W. H. Weinberg, J. Am. Chem. Soc., 1996, 118, 7225-7226; (b) A. Bansal and N. S. Lewis, J. Phys. Chem. B, 1998, 102, 1067-1070; (c) A. Bansal and N. S. Lewis, J. Phys. Chem. B, 1998, 102, 4058-4060; (d) L. J. Webb and N. S. Lewis, J. Phys. Chem. B, 2003, 107, 5404-5412; (e) E. J. Nemanick, P. T. Hurley, B. S. Brunschwig and N. S. Lewis, J. Phys. Chem. B, 2006, 110, 14800-14808; (f) R. Hunger, R. Fritsche, B. Jaeckel, W. Jaegermann, L. J. Webb and N. S. Lewis, Phys. Rev. B: Condens. Matter, 2005, 72, 4531745317.

7 (a) A. Bansal and N. S. Lewis, J. Phys. Chem. B, 1998, 102, 4058-4060; (b) W. J. Royea, A. Juang and N. S. Lewis, Appl. Phys. Lett., 2000, 77, 1988-1990; (c) H. Yu, L. J. Webb, J. R. Heath and N. S. Lewis, Appl. Phys. Lett., 2006, 88, 252111-252113.

8 L. E. O'Leary, E. Johansson, B. S. Brunschwig and N. S. Lewis, J. Phys. Chem. B, 2010, 114, 14298-14302.

9 L. E. O'Leary, M. J. Rose, T. X. Ding, E. Johansson, B. S. Brunschwig and N. S. Lewis, J. Am. Chem. Soc., 2013, 135, 10081-10090.

10 J. R. C. Lattimer, B. S. Brunschwig, N. S. Lewis and H. B. Gray, J. Phys. Chem. C, 2013, 117, 27012-27022.

11 (a) U. Kölle and M. Grätzel, Angew. Chem., 1987, 99, 572574; (b) U. Kölle and M. Grützel, Angew. Chem., Int. Ed. Engl., 1987, 26, 567-570; (c) U. Kölle, B. S. Kang, P. Infelta, P. Comte and M. Grätzel, Chem. Ber., 1989, 122, 1869-1880; (d) S. Cosnier, A. Deronzier and N. Vlachopoulos, J. Chem. Soc., Chem. Commun., 1989, 1259-1261; (e) G. Mestroni, G. Zassinovich and A. Camus, J. Organomet. Chem., 1977, 140, 63-72; $(f)$ E. Steckhan, S. Herrmann, R. Ruppert, E. Dietz, M. Frede and E. Spika, Organometallics, 1991, 10, 1568-1577; $(g)$ H. C. Lo, C. Leiva, O. Buriez, J. B. Kerr, M. M. Olmstead and R. H. Fish, Inorg. Chem., 2001, 40, 6705-6716.

12 M. A. Bennett, G. Chung, D. C. R. Hockless, H. Neumann and A. C. Willis, J. Chem. Soc., Dalton Trans., 1999, 34513462.
13 (a) A. El-Hendawy, S. Alqaradawi and H. Al-Madfa, Transition Met. Chem., 2000, 25, 572-578; (b) A. Wu, J. Masland, R. D. Swartz, W. Kaminsky and J. M. Mayer, Inorg. Chem., 2007, 46, 11190-11201.

14 (a) In solution, the $\mathrm{Ru}(\mathrm{II})$ form of compound 5 was readily oxidized by $\mathrm{O}_{2}$ from $\mathrm{Ru}(\mathrm{II})$ to $\mathrm{Ru}(\mathrm{III})$. This is consistent with the observed redox potential for the $\mathrm{Ru}^{\mathrm{III} / \mathrm{II}}$ couple near -0.5 V $(b)$ A. Endo, Y. Hoshino, K. Hirakata, Y. Takeuchi, K. Shimizu, Y. Furushima, H. Ikeuchi and G. P. Sato, Bull. Chem. Soc. Jpn., 1989, 62, 709-716.

15 For this work, a single monolayer implies an equal number of $\mathrm{Si}(111)$ atop sites and the moiety in question (e.g., bipyridyl).

16 (a) C. Ferrgina and M. Massucci, J. Inclusion Phenom. Mol. Recognit. Chem., 1989, 7, 529; (b) Notably, any attempt to drop-cast unmetallated 2,2'-bipyridyl onto copper foil to obtain an XP spectrum failed. After several attempts, closer examination of the samples revealed that the bipyridine was lost by sublimation under the high vacuum conditions of the spectrometer.

17 (a) K. Sardar, J. Fisher, D. Thompsett, M. R. Lees, G. J. Clarkson, J. Sloan, R. J. Kashtiban and R. I. Walton, Chem. Sci., 2011, 2, 1573-1578; (b) M. T. Vagnini, M. W. Mara, M. R. Harpham, J. Huang, M. L. Shelby, L. X. Chen and M. R. Wasielewski, Chem. Sci., 2013, 4, 3863-3873.

18 K. Oomura, D. Ooyama, Y. Satoh, N. Nagao, H. Nagao, F. S. Howell and M. Mukaida, Inorg. Chim. Acta, 1998, 269, 342-346.

19 W. Kaim, R. Reinhardt, E. Waldhoer and J. Fiedler, J. Organomet. Chem., 1996, 524, 195-202.

20 (a) A. J. Bard and L. R. Faulkner, Electrochemical Methods: Fundamentals and Applications, John Wiley and Sons, Hoboken, NJ, 2nd edn, 2001; (b) J.-M. Saveant, Elements of Molecular and Biomolecular Electrochemistry, Wiley, Hoboken, NJ, 2006.

21 Voltammetry of the mixed bipyridyl/methyl surface showed an irreversible reduction event $-1.3 \mathrm{~V} v s . \mathrm{Fc}^{+/ 0}$, although this process was obscured by other background currents in some experiments (see ESI $\dagger$ ).

22 M. Ladwig and W. Kaim, J. Organomet. Chem., 1992, 439, 79-90.

23 (a) D. P. Harrison, A. M. Lapides, R. A. Binstead, J. J. Concepcion, M. A. Mendez, D. A. Torelli, J. L. Templeton and T. J. Meyer, Inorg. Chem., 2013, 52, 4747-4749; (b) J. M. Calvert, R. H. Schmehl, B. P. Sullivan, J. S. Facci, T. J. Meyer and R. W. Murray, Inorg. Chem., 1983, 22, 2151-2162. 